\title{
The impact of location and type on the performance of Low-Voltage network connected Battery Energy Storage Systems
}

Article

Accepted Version

Yunusov, T., Frame, D., Holderbaum, W. and Potter, B. (2016) The impact of location and type on the performance of LowVoltage network connected Battery Energy Storage Systems. Applied Energy, 165. pp. 202-213. ISSN 03062619 doi: https://doi.org/10.1016/j.apenergy.2015.12.045 Available at https://centaur.reading.ac.uk/57178/

It is advisable to refer to the publisher's version if you intend to cite from the work. See Guidance on citing.

Published version at: http://dx.doi.org/10.1016/j. apenergy.2015.12.045

To link to this article DOI: http://dx.doi.org/10.1016/j.apenergy.2015.12.045

Publisher: Elsevier

All outputs in CentAUR are protected by Intellectual Property Rights law, including copyright law. Copyright and IPR is retained by the creators or other copyright holders. Terms and conditions for use of this material are defined in the End User Agreement. 


\section{CentAUR}

Central Archive at the University of Reading

Reading's research outputs online 


\title{
The Impact of Location and Type on the Performance of Low-Voltage Network Connected Battery Energy Storage Systems
}

\author{
Timur Yunusov ${ }^{\mathrm{a}}$, Damien Frame ${ }^{\mathrm{b}}$, William Holderbaum ${ }^{\mathrm{a}}$, Ben Potter ${ }^{\mathrm{a}}$ \\ ${ }^{a}$ University of Reading, Reading, $U K$, RG6 6AH \\ ${ }^{b}$ University of Strathclyde, Glasgow, UK, G1 $1 X W$
}

\begin{abstract}
This paper assesses the impact of the location and configuration of Battery Energy Storage Systems (BESS) on LowVoltage (LV) feeders. BESS are now being deployed on LV networks by Distribution Network Operators (DNOs) as an alternative to conventional reinforcement (e.g. upgrading cables and transformers) in response to increased electricity demand from new technologies such as electric vehicles. By storing energy during periods of low demand and then releasing that energy at times of high demand, the peak demand of a given LV substation on the grid can be reduced therefore mitigating or at least delaying the need for replacement and upgrade. However, existing research into this application of BESS tends to evaluate the aggregated impact of such systems at the substation level and does not systematically consider the impact of the location and configuration of BESS on the voltage profiles, losses and utilisation within a given feeder.

In this paper, four configurations of BESS are considered: single-phase, unlinked three-phase, linked three-phase without storage for phase-balancing only, and linked three-phase with storage. These four configurations are then assessed based on models of two real LV networks. In each case, the impact of the BESS is systematically evaluated at every node in the LV network using Matlab linked with OpenDSS. The location and configuration of a BESS is shown to be critical when seeking the best overall network impact or when considering specific impacts on voltage, losses, or utilisation separately. Furthermore, the paper also demonstrates that phase-balancing without energy storage can provide much of the gains on unbalanced networks compared to systems with energy storage.
\end{abstract}

Keywords: Energy Storage, Smart Grid, Battery, LV Networks, Control

\section{Introduction}

The transition to a low carbon economy is a major focus of energy policy in the UK and internationally as governments respond to challenging environmental targets [1, 2]. In particular, the decarbonisation of the heat and transport sectors are areas of significant strategic focus and Low Carbon Technology (LCT) such as photovoltaic $(\mathrm{PV})$ generation, electric vehicles $(\mathrm{EV})$ and heat pumps (HP) are expected to make significant contributions to this transition [3, 4].

As domestic consumers adopt these low-carbon technologies (LCTs) in greater numbers and the penetration of such technologies within the network increases, the distribution networks will come under increased stress. Furthermore, the uptake is expected to not be evenly distributed with clusters forming in the early stages

Email address: b.a.potter@reading .ac.uk (Ben Potter) of adoption leading to certain LV networks exceeding their constraints even at low national adoption rates [5]. However, traditional planning approaches are not fitfor-purpose for this uptake of LCTs. For low-voltage (LV) networks, traditional planning commonly utilises established understanding of diversity where After Diversity Maximum Demand (ADMD) values are applied to voltage drop and loading calculations. Unchanged for many years, these methods are based on historical load analysis and incorporate standard load growth assumptions that are no longer valid. Furthermore, once installed, the networks are generally unmonitored.

DNOs are aware that changes are needed in the planning process and analysis of future network trends has predicted distribution network operators will become more active in operating via innovation in the use of existing and new technologies [6]. The Smart Grid which, although varying definitions exist, is often described in terms of a power system with increased use of innova- 
tive technology is considered essential in order to facilitate the low carbon transition [7, 8, 9], and so these changes and associated challenges can not be avoided.

Traditional network reinforcement solutions involve adjustment of secondary transformer tap settings followed by asset upgrade (e.g. transformer upgrade and line re-conductoring) where the impact from changing the tap settings is insufficient. As a technical solution that avoids directly interfacing with customers to alter demand and generation profiles, Battery Energy Storage Systems (BESS) are receiving increased attention in academic studies and industrial trials. By locating BESS at strategic locations within the distribution network, power flows can be managed and benefits achieved in terms of voltage profile, cable loading (line utilisation) and losses. Appropriate charging and discharging can offset excessive voltage rise and reversepower flow due to PV installations, excessive voltage drop and thermal overloads due to new LCT load, and in general improve losses through peak demand reduction. However, these benefits are often assessed in aggregation, and so don't consider the location of the BESS within the LV feeder, or are considered in isolation and assume that a location that is ideal for voltage, for example, is also ideal for peak power flow. This paper will demonstrate that this assumption is in most cases not valid and the in general location within the feeder is a critical consideration when trying to maximise the benefits from BESS.

A number of BESS were installed and trialled in the UK distribution networks. Above the LV level, the main purpose of BESS is to provide support for primary substations and mitigate operational constraints [10,11] or provide balancing services and reduce curtailment of renewable generation [12]. In these cases, the anticipated impact of BESS is known, as the distribution networks at medium voltage are closely monitored. On the LV network, BESS have been installed within the customer premises aiming to increase self-consumption of domestic PV generations and making use of time-of-use tariffs [13]. Community energy storage has been trialled to support the LV feeder through peak shaving and reactive power injection/absorption [14]. BESS have also been deployed on LV feeders at the street-level, owned and controlled by the DNO, in order to reduce peak demand on a given feeder as well as to address voltage constraints and harmonics [15].

In all the cases described above, forecasting at least day-ahead power and energy demand is essential in order to optimise management of the BESS. Set-point based control methods, that operate a battery rather like a thermostat regulates temperature and charge or dis- charge based on one or more thresholds, are able to demonstrate a net positive impact but achieve far from optimal performance and so often require bigger batteries for the same gain compared to forecast-based methods. By incorporating an expectation of future demand, albeit with a level of uncertainty that must be taken into account, control methods that include forecasts are able to outperform set-point based methods by reserving headroom for the periods of lowest demand and capacity for the periods of highest demand in the day [16, 17].

In practical situations, the feasible installation locations and configurations of storage units may be limited. Field trial deployments have used engineering judgement and product availability to configure and locate BESS in distribution networks to evaluate benefits [18, 14]. Further evaluation indicates that practical BESS deployments can support voltage and power flow events but should not be expected to provide a solution to all events at all times. Establishing the business case requires maximising the benefits against multiple objectives and realising the full potential of the technology. Paying attention to the impact of the location of the BESS within a feeder is one key part maximising these benefits.

The work presented in this paper is motivated by the LCNF New Thames Valley Vision Project (NTVV) where BESS have been installed on the LV network at the street level and are operated by the DNO [19]. Assuming access to retrospective smart meter data but limited real-time network monitoring, the existing control strategy for these BESS is to forecast individual endpoint (e.g. household) load profiles, aggregate them at the substation level, and then determine the charge and discharge schedule for the BESS on a per phase basis that minimises the overall daily peak demand seen at the substation. However, although the result of this peak reduction is improved voltage profile, cable loading and losses upstream of the BESS, LV feeder conditions are not explicitly included in the control strategy and the potential benefits to the LV network are not considered. This paper builds on the existing scheduling algorithm work and addresses this issue of how best to locate and operate such BESS units in LV networks for maximum overall benefit within the LV network itself. The paper develops an analytical method for the positioning of known configurations of BESS, operating in the peak reduction mode described above, on LV feeders for maximum benefit to the LV network conditions. 


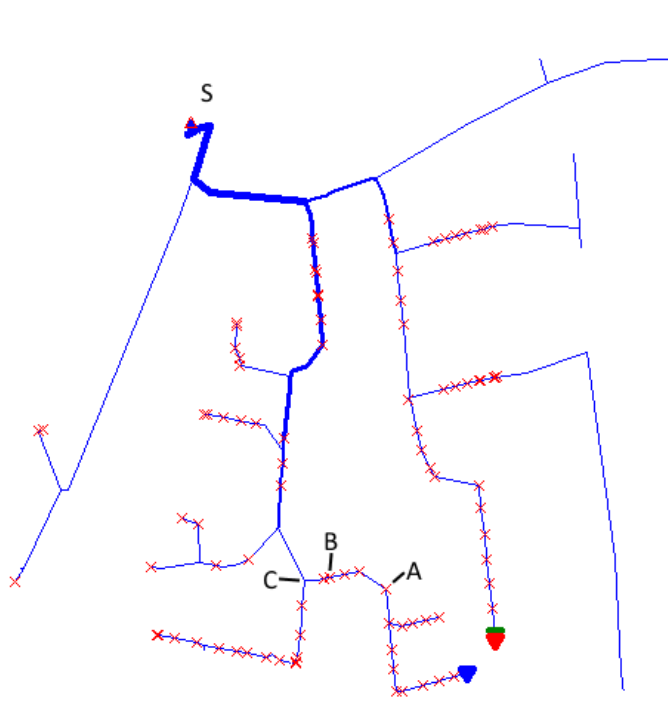

(a) Network 1
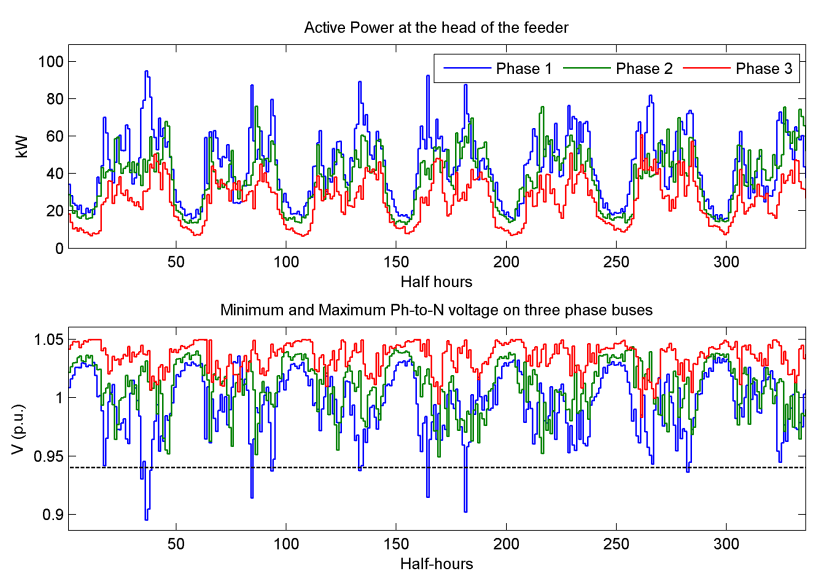

(c) Network 1: 118 customers.

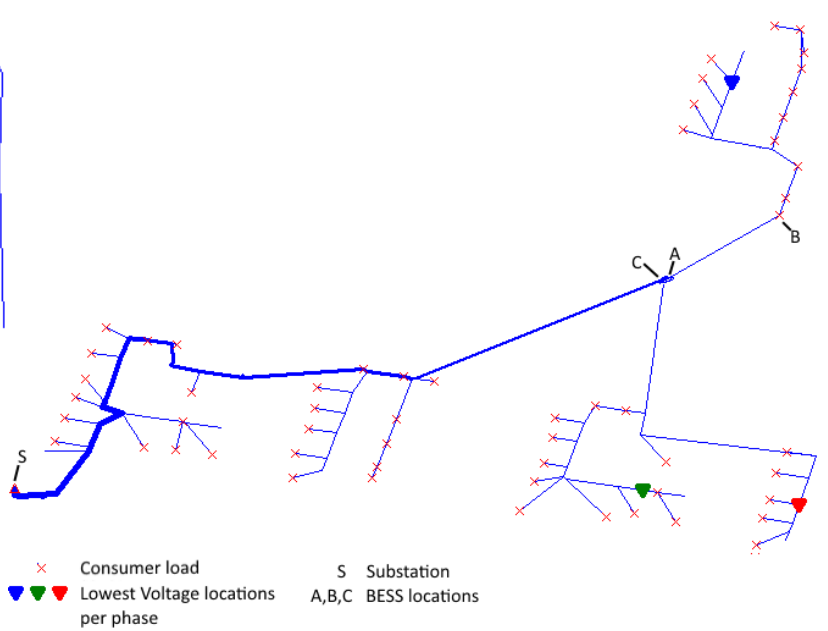

(b) Network 2
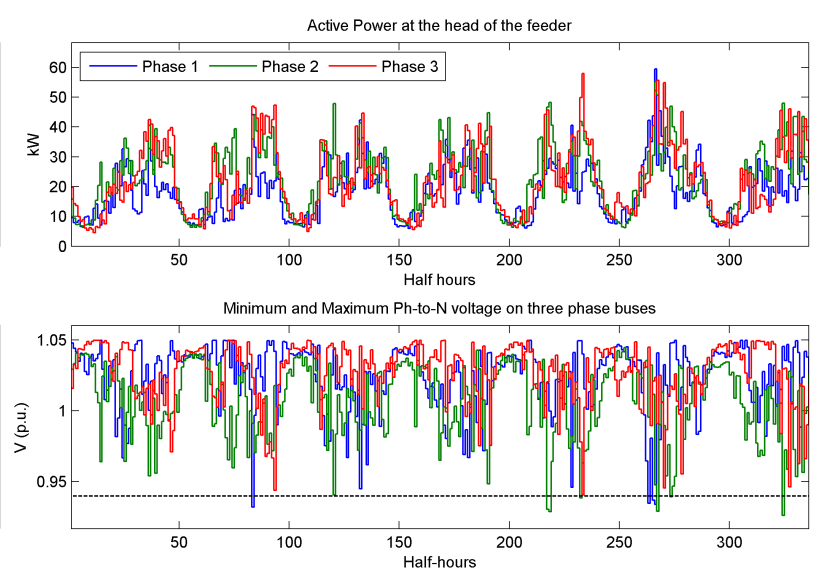

(d) Network 2: 56 customers.

Figure 1: Case Study Feeder Schematics and Baseline Results

\section{Methodology}

The impact of various BESS peak configurations and associated control algorithm, on real LV networks under worst case loading conditions, is assessed in order to establish the key considerations and trade-off's between a range of network performance metrics and BESS location. The LV networks selected, described in detail in Section 2.1, are real urban LV feeders with common characteristics such as multiple branches and singlephase spurs. Furthermore, existing demand is pushing the operational conditions of these networks outside the statutory limits. Examining real networks instead of a theoretical, simple radial feeder helps to highlight the complexities of real networks. However, as discussed further in Section 2.1.1, real smart meter data for individual customers from a separate study is used to drive the models in this paper. Nevertheless, network constraints on the two networks are also breached in the results presented later in the paper suggesting that the reason for these violations is partially due to the existing network structure.

The configurations and algorithms, explained in detail in Section 3 , illustrate a range of operational examples and highlight key issues, but are not necessarily intended as optimal or best-in-class exemplars. The selected configurations and algorithms do highlight the separate role of power electronics and energy storage 
in terms of both phase-balancing and peak reduction, which is not commonly considered in the literature. The algorithms used in this paper seek to reduce the peak power demand during day and do not take into account voltage, losses or utilisation. However, the impact of those peak-reduction algorithms are on voltage, losses and utilisation is considered and forms the main body of results. Although algorithms could certainly be written that do seek to balance all of these metrics, it is not necessary to do so for the impact study presented in this paper.

In order to assess the impact of the location of the BESS, in each configuration, the BESS is located at each node in each networks and the network is then simulated using OpenDSS.

\subsection{Network Models}

The two LV network models used in this paper are based on two real LV networks located within the Thames Valley Vision Project. Network 1, shown in Figure 1a. was selected to represent a typical a LV feeder with an unbalanced number of end-points on each phase whereas Network 2 (42 customers on Phase 1, 43 customers on Phase 2, and 32 customers on Phase 3 ), shown in Figure 1b, was selected to represent a typical a LV feeder a more balanced number of end-points on each phase (18 customers on phase 1, 20 customers on Phase 2, and 18 customers on Phase 3 ).

These two LV networks have been modelled in OpenDSS, the open source distribution system simulator developed by EPRI. In OpenDSS all phases are modelled, allowing unbalanced load flow and examination of neutral currents. Utilising the COM interface of OpenDSS, all data processing and scripting is carried out in Matlab with OpenDSS providing network modelling and load flow functionality.

\subsubsection{Demand Data}

Smart meter trial data made publicly available by Irelands Commission for Energy Regulation [20] has been used to allocate real domestic load profiles to the case study feeders. An estimated worst case winter week was chosen from the smart meter data set. Profiles were then randomly selected from the pool and allocated to each of the case study loads. The profiles are half hourly $\mathrm{kWs}$ and for simplicity, the power factor is assumed to be unity.

\subsubsection{Baseline Simulation}

For each network shown in Figure 1 , the chosen winter week has been simulated to provide a baseline of network performance for node voltages, $\mathrm{kW}$ profile at the feeder head (substation), and maximum cable loading under the simulated load conditions. Nodal voltages are assessed against the ESQCR standards adopted by UK DNOs under the Distribution Code; supply voltage must be within $+10 /-6 \%$ of nominal $230 \mathrm{~V}$ [21]. Cable loading is assessed against the rated continuous capacity.

As can be seen in Figure 1c the unbalanced load connection of Network 1 causes significant overloading of Phase 1 (blue trace) with minimum voltage on days 1 and 4. The locations of the worst observed minimum voltage are highlighted in Figure 1a with blue, green and red triangle for Phases 1, 2 and 3 respectively.

Although Network 2 has a more balanced load connection a degree of unbalance is still evident, as is inevitable at this level of disaggregation of load and asynchronous consumer behaviour. Under these worst case conditions, minimum voltage level on Phase 1 and 2 has breached the limit on several occasions. On the day 6 , due to high demand on all three phases, Phases 1 and 2 breach the minimum voltage limit within the same hour.

Both case study examples represent LV networks that are experiencing voltage and thermal breaches of operational limits. As discussed in the introductory sections, the application of BESS to resolve such LV network issues is an increasingly viable option for DNOs. For example, power injection on Phase 1 at the end of the branch with the worst voltage problem during peak hours would alleviate the voltage issues. The following sections of this paper will investigate in detail the role the BESS can play in supporting operation of these two networks and the impact of location on performance.

\section{BESS Configurations and Scheduling Algorithms}

Four different BESS operational configurations are considered in this paper: a single-phase BESS connected to the most heavily loaded phase on a feeder; three single-phase, independently operated and colocated BESS's, connected to all three-phases at a common location on a feeder; a three-phase BESS that is able to use power electronics to move energy between phases and performs this phase-balancing function without using any energy storage capacity; and finally a three-phase BESS that is able to perform both phase-balancing and peak reduction using battery energy storage. The following subsections describe each of these configurations in more detail and also the algorithm that is used in each case to determine the operational power profile of the BESS. Once the charge and 
discharge power profile for the BESS has been determined based on aggregated data, this profile is re-used for every location on the feeder that the BESS is trialled. The algorithms and presented here are intended to facilitate an investigation into the impact of such approaches on the resulting performance of the BESS. More advanced algorithms can certainly be developed and such development should be encouraged.

Several assumptions are made in the generation of the BESS charge and discharge schedules in the interest of simplifying the control approach:

- The scheduling algorithm has access to perfect forecasts of daily energy demand. The authors, and other researchers, have developed algorithms that don't make this assumption and include a real-time correct element [17, 22, 23]. However, such algorithms do not significantly impact the key points addressed in this paper.

- The aim of the BESS scheduling algorithm is to reduce the maximum daily energy demand peak on the feeder as measured at the substation. Although alternative strategies exist, such as direct voltage control, peak reduction is commonly used in the literature and is an appropriate choice for comparison purposes.

- Energy stored within the BESS for the minimum amount of time in order to release the resources of BESS for other functions e.g. arbitrage or peak reduction at higher levels of distribution network. In the content of the New Thames Valley Vision project, as well as much of the emerging literature, it is recognised that for BESS to be cost effective, they will need to perform more than one function [16, 24, 25].

- The maximum charge and discharge rate is constant for all levels of BESS state of charge. This approximation does not have a significant impact on the key issues addressed in this paper.

- The BESS scheduling algorithm presented in this paper is not intended for long-term control and hence does not take into account impact of storage cycling on the operational lifetime of the battery.

The following sub-sections describe each of the BESS configurations and associated control algorithms. Example charge and discharge schedules are generated for day 1 of the worst-case week previously identified for Network 1 only.

\subsection{Configuration 1: Single-phase BESS on one phase}

One use-case for a BESS is to alleviate voltage and current issues on the most heavily loaded phase of a three-phase feeder. It may be considered unnecessary to install a BESS on every phase, or install a three-phase system when the the heavy loading on one phase is due to more customers being connected to that phase compared to the others. In this case, the cause of the phaseimbalance is a fundamental part of the feeder structure. Configuration 1 seeks to represent this case of a singlephase BESS connected to a single-phase of a feeder. Phase-balancing in this configuration is impossible as the BESS is only connected to one phase.

The algorithm used for Configuration 1 uses the Matlab optimisation solver to minimise the cost function given in equation (1). This cost function aims to minimise the maximum peak demand under the BESS operation within the control horizon such that the time duration of energy stored in the battery is also minimised, in line with the assumptions previously stated.

$$
\text { minimise } \max \left(\sum_{k}^{48}\left(D_{f}(k)+P(k)\right)^{2}\right)+\alpha \sum_{k}^{48} C(k)
$$

Subject to following constraints:

$$
\begin{aligned}
C_{\text {min }} & \leq C(k) \leq C_{\text {max }} \\
-P_{\text {max }} & \leq P(k) \leq P_{\text {max }} \\
C(k) & =C(k-1)+\eta \tau P(k) \\
\eta & = \begin{cases}\eta & \text { if } P(k) \geq 0, \\
\frac{1}{\eta} & \text { if } P(k)<0 .\end{cases}
\end{aligned}
$$

where $D_{f}(k)$ - vector of forecasted aggregate demand at time $k$ for the feeder in question and the phase where BESS in installed; $P(k)$ - power flow from BESS to network on a single phase at time $k ; \alpha$-weighting of total energy stored in BESS over the day; $C(k)$ - energy stored in BESS in kWh at time $k ; C_{\max }$ and $C_{\text {min }}$ - maximum and minimum constrains on BESS energy capacity; $P_{\text {max }}$ - maximum rating of BESS for charge and discharge; $\eta$ - BESS efficiency and $\tau$ - duration of time period in hours. Constraints given in equations (2) - (5) represent the physical constraints on power electronics, energy storage capacity and energy storage model with separate charge and discharge efficiencies.

The resultant BESS schedule and state of charge profile for Phase 1 of day 1 of Network 1 is given in figure $2 \mathrm{a}$

\subsection{Configuration 2: Three single-phase storage}

Previous trials showed that separate single-phase storage can be effective in supporting network operation 


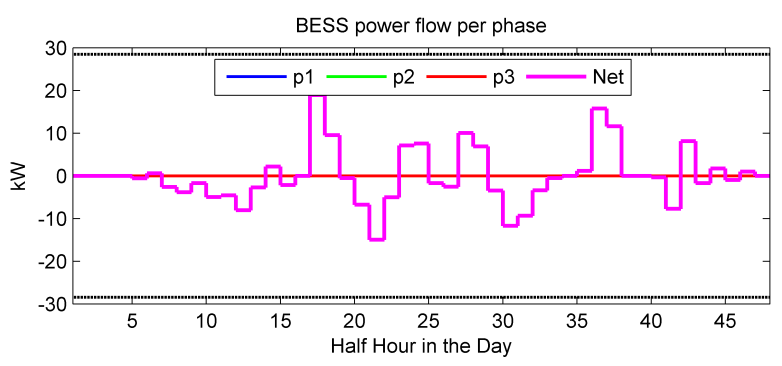

Energy stored in BESS (kWh)

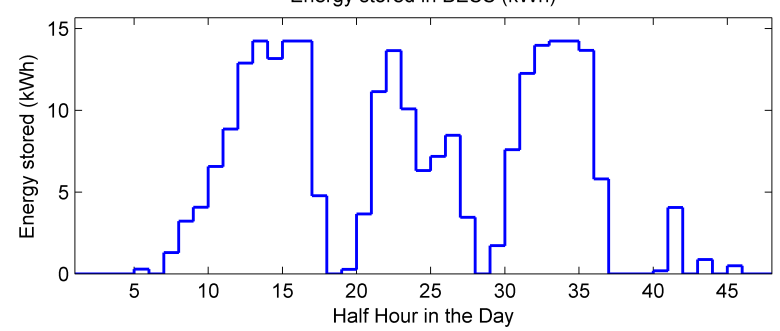

(a) BESS schedule and SoC for Configuration 1 (single-phase BESS) for Network 1, day 1
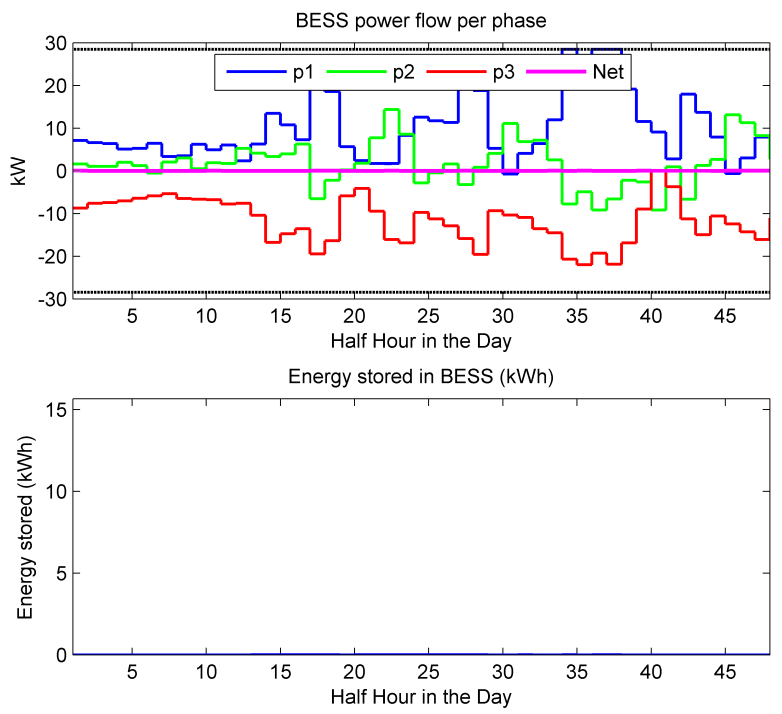

(c) BESS schedule and SoC for Configuration 2 (three-phase power electronics) for Network 1, day 1

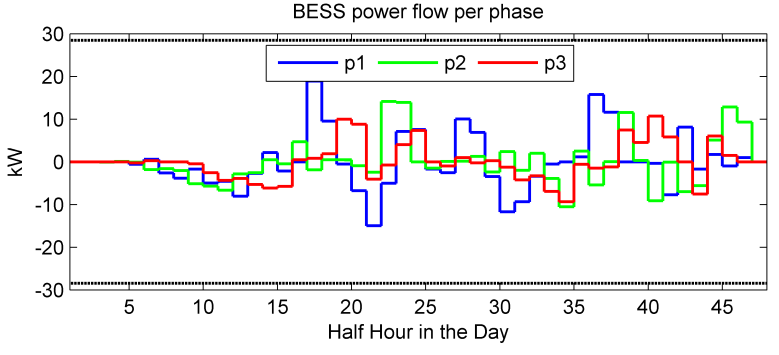

Energy stored in BESS (kWh)

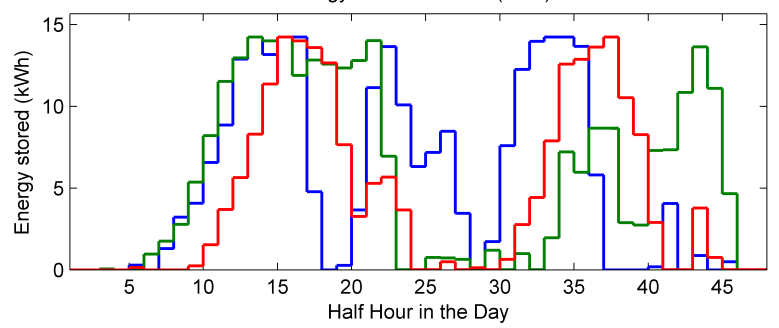

(b) BESS schedule and SoC for Configuration 2 (three singlephase BESS) for Network 1, day 1
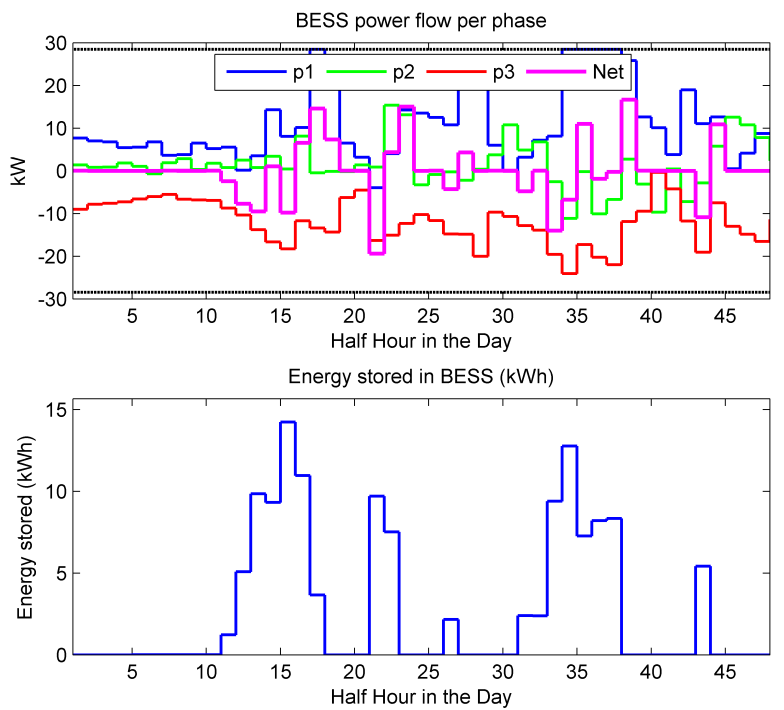

(d) BESS schedule and SoC for Configuration 4 (three-phase BESS) for Network 1, day 1

Figure 2: Scheduled power flows from the BESS into network and the resultant state-of-charge profiles for each BESS configuration

to maintain voltage levels and perform peak reduction [14]. Configuration 2 represents this case by co-locating three-single phase BESS. Each single-phase BESS is treated in the same way as in configuration 1 (including capacity and rating) and the schedule is developed to reduce peaks on each phase independently. Although uncoordinated between phases in this example, coordinated BESS across multiple phases can potentially perform limited phase-balancing using the energy storage component.

Similarly to configuration 1 , figure $2 \mathrm{~b}$ shows three BESS schedules, one per phase, and state of charge profiles based on demand data for each phase on day 1 of Network 1.

\subsection{Configuration 3: Three-phase power electronics for phase balancing}

Volatile customer behaviour and unbalanced customer connections means power flow across phases are 


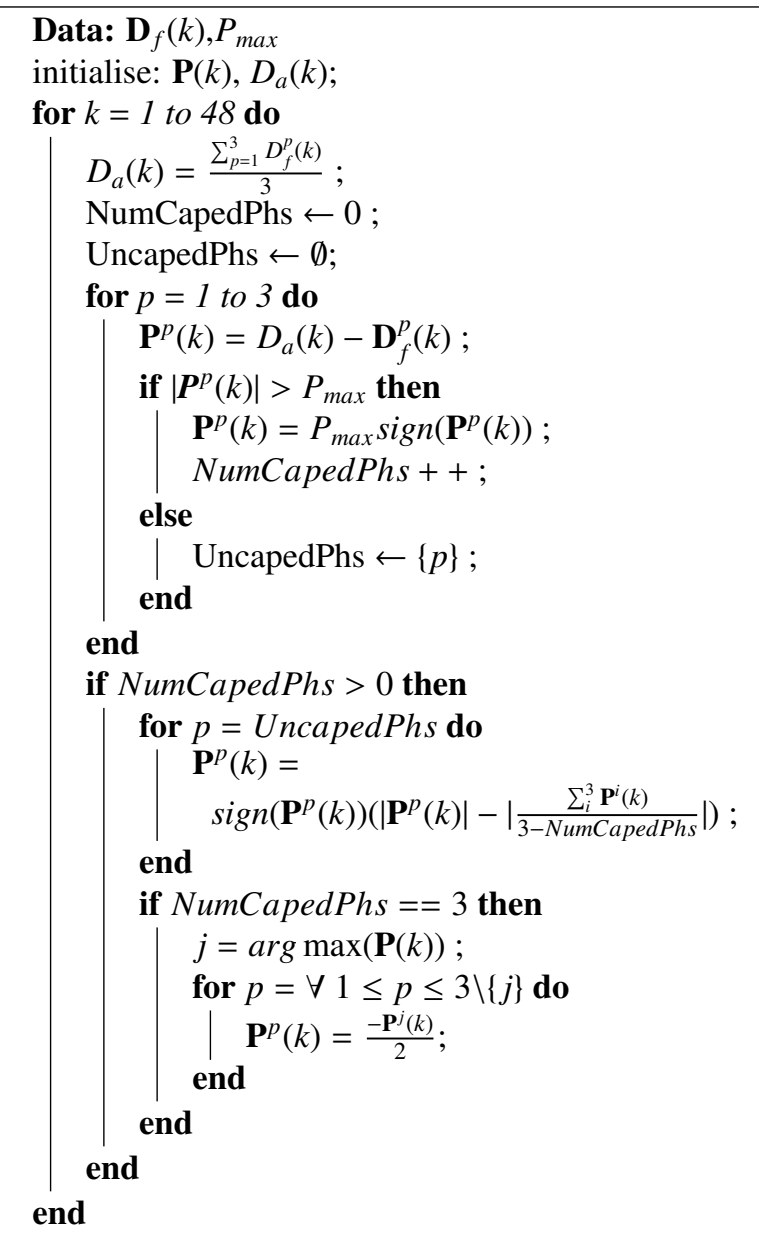

Algorithm 1: Algorithm for arithmetic phasebalancing function

rarely balanced, causing voltage unbalance [26, 27]. Consequently, balancing of active power could reduce individual peaks on each phase and improve voltage. Furthermore, the cost of three-phase power electronics would be lower than a lithium ion-based energy storage device. In contrast to Configuration 2, a three-phase connected BESS is capable of phase-balancing without using the storage element.

The algorithm used for Configuration 3 for arithmetic phase-balancing is given below in algorithm 1 . This algorithm computes the average power across all phases for each time-step and then determines the BESS power flow on each phase that will bring the current power as close to this average as possible.

Applying phase balancing algorithms to the forecasted demand for day 1 of Network 1 creates the power flow schedule for each phase depicted in figure $2 \mathrm{c}$. The SoC plot for configuration is included for completeness but shows no data as the energy storage component is not used in this configuration.

\subsection{Configuration 4: Three-phase-balancing com- bined with energy storage}

The benefit of phase-balancing function is evident for unbalanced feeders with asynchronous customer behaviour. However, social events or TV programmes could cause synchronous customer demand causing peaks on all three phases simultaneously that cannot be resolved with phase balancing only.

BESS configuration 4 is designed to represent the energy storage and management devices deployed in the Bracknell area in UK as part of NTVV project. Each device consists of three-phase power electronics capable of performing a phase-balancing function and modular energy storage with total capacity of a single-phase BESS presented in configuration 1. Therefore, this device combines the benefits of balancing power between phases with energy time shifting with energy storage.

A day-ahead schedule for each phase is generated from forecasted demand with an aim to minimise following cost function:

$$
\begin{aligned}
\text { minimise } \max & \left(\sum_{k}^{48}\left(\hat{\mathbf{D}}_{f}(k)\right)^{2}\right)+\alpha \sum_{k}^{48} C(k)+ \\
& \sum_{k}^{48}(\max (\boldsymbol{\Phi}(k)))
\end{aligned}
$$

where

$$
\begin{gathered}
\hat{\mathbf{D}}_{f}(k)=\mathbf{D}_{f}(k)+\mathbf{P}(k) \\
\boldsymbol{\Phi}(k)= \\
\left\{\left(\hat{\mathbf{D}}_{f}^{1}(k)-\hat{\mathbf{D}}_{f}^{2}(k)\right)^{2},\left(\hat{\mathbf{D}}_{f}^{2}(k)-\hat{\mathbf{D}}_{f}^{3}(k)\right)^{2},\left(\hat{\mathbf{D}}_{f}^{3}(k)-\hat{\mathbf{D}}_{f}^{1}(k)\right)^{2}\right\}
\end{gathered}
$$

Subject to following constraints:

$$
\begin{aligned}
C_{\text {min }} & \leq C(k) \leq C_{\text {max }} \\
-P_{\text {max }} & \leq P^{p}(k) \leq P_{\text {max }}, p=1,2,3 \\
C(k) & =C(k-1)+\eta \tau \sum_{p}^{3} P^{p}(k) \\
\eta & = \begin{cases}\eta & \text { if } \sum_{p}^{3} P^{p}(k) \geq 0, \\
\frac{1}{\eta} & \text { if } \sum_{p}^{3} P^{p}(k)<0 .\end{cases}
\end{aligned}
$$

where, $\hat{\mathbf{D}}_{f}(k)$ is the expected demand under BESS operation per phase at time $k ; \boldsymbol{\Phi}(k)$ is the demand difference between phases under BESS operation at time $k$; 
$\mathbf{D}_{f}(k)$ is the matrix with forecasted aggregated demand on each phase at time $k ; \mathbf{P}(k)$ is the power flow on each phase from BESS at time $k$. The constraints given in equations $(9)$ - (12) are equivalent to $(2)$ - (5) for threephase operation.

As per the other configurations, the resulting power flow schedule per phase, and SoC, can be seen in $2 \mathrm{~d}$

\section{Case Study Analysis}

In this section, scheduling algorithms are applied to the case study LV networks and the impact of location on key network parameters are evaluated for each BESS configuration. The networks are simulated across the full week but for clarity, the worst case day, with highest peak power, is used for the results presented below. For each network and BESS configuration, the minimum voltage, maximum line overload per phase and total losses observed during the day are taken as the performance metrics. This process is repeated for each possible location (all three-phase buses) of the BESS on the network. Detailed results are presented for Network 1 and then comparative summary results are presented for Network 2.

\subsection{Network 1 location analysis \\ 4.1.1. Configuration 1: Single-phase BESS on one phase}

Due to highest peak demand, caused by greater number of customers on Phase 1, the single-phase BESS device connected to Phase 1 and was tried on all threephase locations. The BESS is sized at $30 \%$ of the highest peak half-hourly energy consumption on the phase and scheduled to reduce peak demand as per cost function in 1

In Figure 3a, the losses, utilisation per phase and minimum voltage per phase is plotted as a function of the nodal location of the BESS. The impact of BESS location on losses is not significant reaching $95 \mathrm{kWh}$ around Buses $60-95$ and up to $100 \mathrm{kWh}$ at the end of the feeder. However, the minimum voltage on Phase 1 can be significantly improved by locating the BESS around Buses 66-81.

Single-phase BESS only impacts the power flow on one phase therefore line utilisation is only improved on the phase that the BESS is connected to. The lowest line utilisation on Phase 1 is achieved by locating BESS on buses 18-95, yet the current flow through the feeder is still above the recommended line rating. Beyond bus 95, the BESS is located on a branch of the feeder and therefore can only offset power flow from the consumers down the line.

\subsubsection{Configuration 2: Single-phase BESS on all three phases}

Similarly to single-phase BESS, in Figure 3b, a similar improvement in the worst-case minimum voltage is achievable but only if the BESS is installed between nodes 60-63, a smaller range than for Configuration 1. As expected, the BESS is now having an influence on all three phases, but the greatest benefit is still achieved by locating the BESS according to Phase 1. Therefore, in this particular example and perhaps more generally for unbalanced LV feeders with one phase more heavily loaded than the others, there is no significant benefit in installing three single-phase BESS, as a similar benefit can be obtained with just one. The impact of additional BESs devices connected to other phases does not improve the overall network condition. Voltage and line utilisation on the heaviest phase still violates the constraints.

\subsubsection{Configuration 3: Three-phase BESS using phase-balancing only}

With reference to Figure $3 \mathrm{c}$, for the phase balancing without storage configuration, more significant variations in impact occur by location. As power is being pulled down one phase to be discharged on another, the trade-off on impacts between phases becomes more evident with location, as does the influence of location on losses. The minimum voltage on Phase 1 improves dramatically between buses 20 and 95 . This improvement occurs against a corresponding degradation in voltage of Phases 2 and 3. Losses vary significantly by location with best positions found around bus 38 and between buses 60-65.

Fundamentally, the overall network performance is significantly improved by using phase-balancing without storage. Locating BESS between buses 38 and 95 mitigates voltage violations on Phase 1 and reduced line utilisation to a level below the maximum recommended rating.

\subsubsection{Configuration 4: Three-phase BESS with full functionality}

As seen in Figure 3d, when storage capacity is added to the phase balancing functionality, the pattern is very similar to the previous configuration with phasebalancing without storage. Instead of transferring power from Phases 2 and 3 to Phase 1, energy storage is used to inject power to Phase 1 . Consequently, Phase 2 and 3 have better line utilisation and higher minimum voltage. Given that for many BESS systems the cost of the energy storage is much higher than for the power electronics, the results presented here suggest that for 

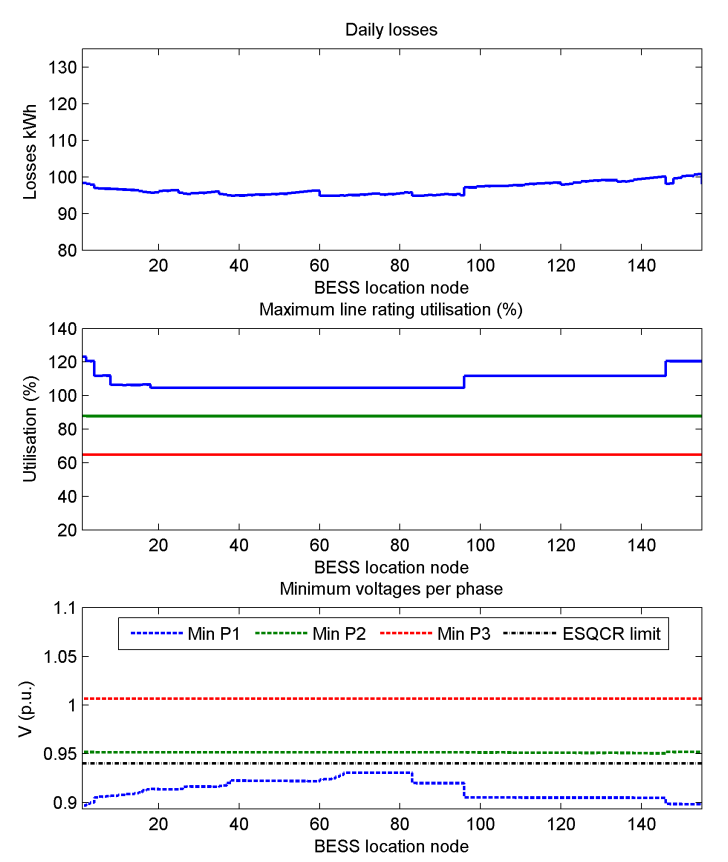

(a) Impact of Configuration 1 (one single-phase BESS on Phase 1)
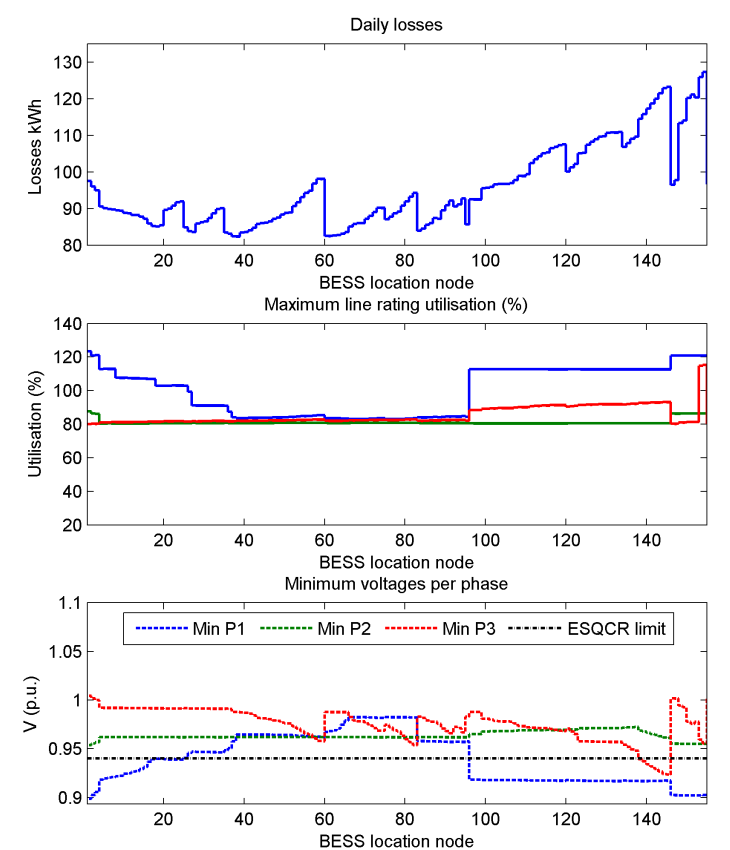

(c) Impact of Configuration 3 (three-phase phase-balancing BESS).
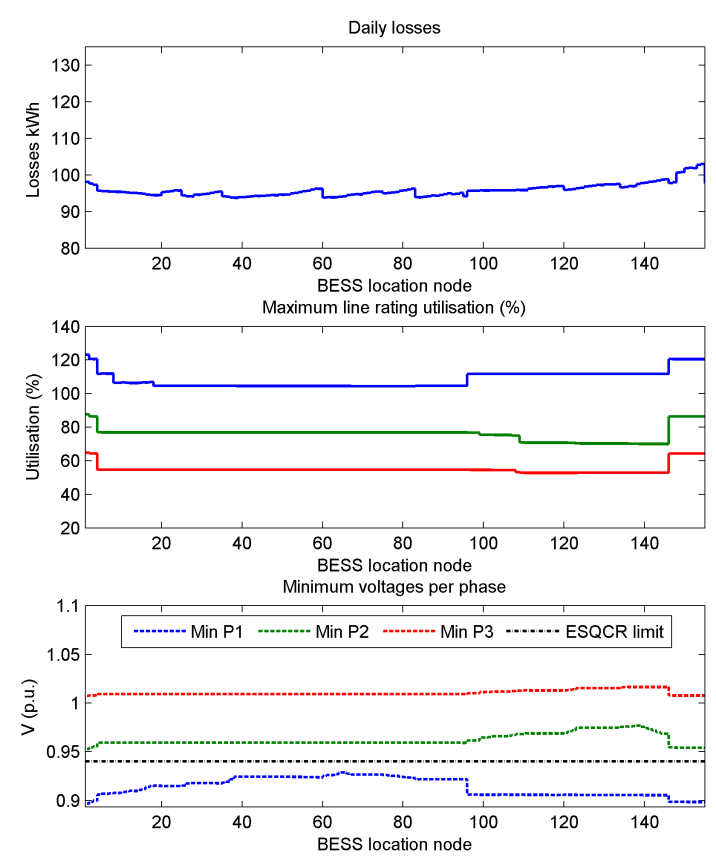

(b) Impact of Configuration 2 (three single-phase BESS).
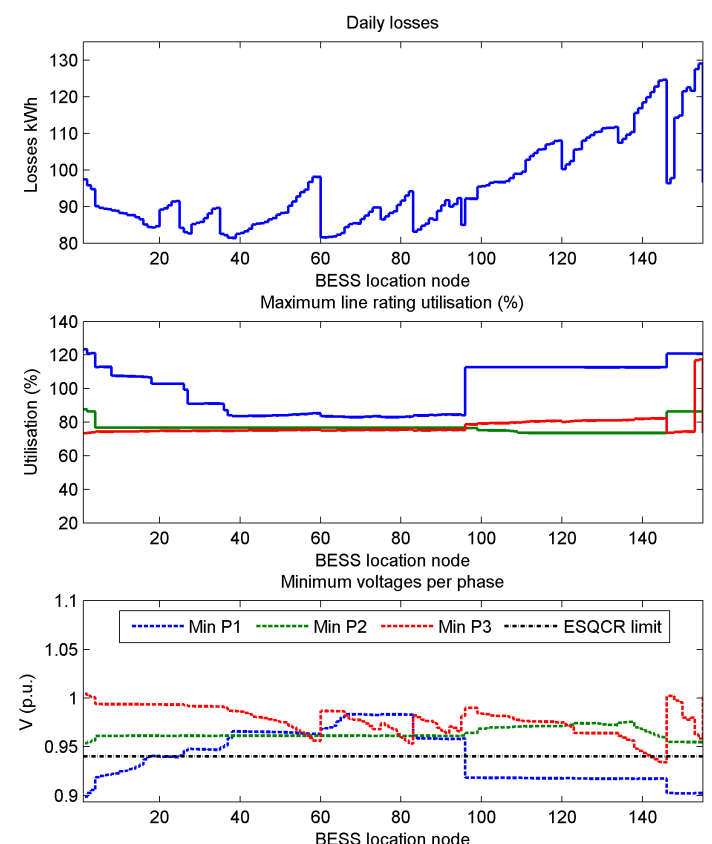

(d) Impact of Configuration 4 (three-phase-balancing with storage function BESS).

Figure 3: Impact of BESS location on the key network operation metrics for each BESS configuration assessed on Network 1.

a LV network feeder with significant phase imbalance it would be more cost effective to install a three-phase power electronics systems without energy storage. 
Table 1: Table for both Networks showing the optimal locations of the BESS for each algorithm and each network

\begin{tabular}{|c|c|c|c|c|c|c|c|c|c|}
\hline & & \multicolumn{4}{|c|}{ Net 1 Best Location (bus number) } & \multicolumn{4}{|c|}{ Net 2 Best Location (bus number) } \\
\hline \multicolumn{2}{|l|}{ BESS configuration } & Losses & Volts & $\min$ p.u. & Overload & Losses & Volts & min p.u. & Overload \\
\hline \multirow{3}{*}{ One single-phase BESS } & $\mathrm{p} 1$ & \multirow{3}{*}{38} & 66 & 0.93 & 94 & \multirow{3}{*}{69} & 78 & 0.94 & 86 \\
\hline & p2 & & 123 & 0.95 & 145 & & 37 & 0.93 & 85 \\
\hline & p3 & & 1 & 1.01 & 82 & & 65 & 0.95 & 79 \\
\hline \multirow{3}{*}{ Three single-phase BESS } & p1 & \multirow{3}{*}{37} & 64 & 0.92 & 82 & \multirow{3}{*}{70} & 78 & 0.94 & 86 \\
\hline & $\mathrm{p} 2$ & & 138 & 0.97 & 142 & & 64 & 0.95 & 54 \\
\hline & p3 & & 135 & 1.02 & 109 & & 38 & 0.99 & 73 \\
\hline \multirow{3}{*}{ Phase-balancing only } & p1 & \multirow{3}{*}{38} & 68 & 0.98 & 68 & \multirow{3}{*}{37} & 50 & 0.95 & 78 \\
\hline & $\mathrm{p} 2$ & & 137 & 0.98 & 4 & & 65 & 0.94 & 1 \\
\hline & p3 & & 1 & 1.00 & 1 & & 70 & 1.00 & 29 \\
\hline \multirow{3}{*}{ Phase-balancing with storage } & p1 & \multirow{3}{*}{37} & 68 & 0.98 & 68 & \multirow{3}{*}{38} & 38 & 0.96 & 38 \\
\hline & p2 & & 136 & 0.98 & 140 & & 59 & 0.96 & 85 \\
\hline & p3 & & 1 & 1.00 & 1 & & 38 & 1.01 & 72 \\
\hline
\end{tabular}

\subsection{Best Location Analysis}

The results presented above inform and set the context for the question of best location of BESS on LV networks. The results obtained in the above analysis identify a best location for each metric, for each phase and are summarised in Table 1 Network 2 has been similarly analysed and results for this network are also included in this table. For Network 1, the best location for improved Phase 1 voltage, regardless of BESS configuration, is around bus 66. A wider set of locations for maximum cable overload can be observed: buses 25 to 95. For losses, the impact of BESS configuration on best location is more evident. With single-phase storage, the location of best voltage improvement and cable loading reduction is near the location with minimum losses, making bus 66 optimal. However, for phase-balancing only and phase-balancing with storage, the location for (a significant) loss reduction and voltage improvement is between buses $38-44$ or $60-68$.

There are several interesting points to be drawn from these results. Firstly, the unbalanced nature of the LV network is essential when considering the impact of BESS at this level of the network. The variation in loading between phases results in clear trade-offs regarding best location for each phase. Secondly, where the BESS is operated in three-phase mode, in an unbalanced fashion, the positive and negative power flows of either charge/discharge cycles or phase-balancing, heavily influence losses. Finally, although there are trade-offs between phases in impact of location, the extent of the network unbalance and relative importance of impact to certain phases must be taken into account when determining the final best location, i.e. for Network 1, Phase 1 conditions are clearly the main priority.

To determine the overall best location for each of the BESS configurations a weighted ranking process is proposed. As described above, for each of the known BESS configurations under assessment, the worst case week scenario is simulated and results recorded. A ranked list of the tested locations can then be derived for each phase and for each metric. If there are known priorities for a specific network, then an appropriate weighting can be applied to each ranked list. For example, with network one, minimum voltage and maximum cable loading on Phase 1 would be prioritised above other metrics as these parameters are exceeding operational limits. The following prioritisation method is proposed based on the assumption that DNO priorities are firstly to operate within the specified limits and secondly to minimise losses. Voltage is assessed in terms of the Voltage Profile $(V P)$ metric across all phases as shown below. Reference voltage, $V_{r e f}$, is 1 p.u. or $230 \mathrm{~V}$ nominal, $N$ is the total number of nodes. A minimum $V P$ represents the least deviation from reference voltage across the network. Nodes on phases with particular voltage problems will dominate and best location for network voltages will be most weighted to locations with most influence on problem nodes and phases.

$$
\mathrm{VP}=\sum_{i}^{N}\left(V_{i}-V_{r e f}\right)^{2}
$$

A similar metric, $C P$ for cable capacity profile is applied to rank location based on cable loading. $M$ is the total number of cables (counting 3 per three-phase line), $C_{r e f}$ 
is the specified maximum $\%$ cable rating $(100 \%$ in this case). The objective is to minimise $C P$.

$$
\mathrm{CP}=\sum_{i}^{M}\left(C_{i} / C_{r e f}\right)^{2}
$$

Using the above assumptions and metrics, the proposed process is:

1. Identify all locations where the network is within operational limits

2. Rank these locations in terms of losses to identify the best location

3 . If no locations achieve operational limits, rank location in terms of voltage and cable loading

Table 2: Highest ranked BESS locations for Both Networks

\begin{tabular}{|c|c|c|}
\hline BESS configuration & Network 1 & Network 2 \\
\hline One single-phase BESS & 66 & 43 \\
\hline Three single-phase BESS & 63 & 70 \\
\hline Phase-balancing only & 38 & 38 \\
\hline Phase-balancing + storage & 38 & 38 \\
\hline
\end{tabular}

Table 2 shows the highest ranked locations for each BESS configuration and network as evaluated on the network improvement metrics on a day with the heaviest loading.

The highest ranked location for one single-phase configuration is marked ' $A$ ' on the figures $1 \mathrm{a}$ and $1 \mathrm{~b}$. For Network 1 this location corresponds to the best improvement on phase with lowest voltage as it experiences the heaviest loading and hence is the priority for improvement. For the Network 2, the highest ranked location for single-phase BESS configuration is a threephase bus just before the branching of the feeder.

BESS Configuration 2 in Network 1 has highest ranked location close to the top of the of the branch with weakest voltage, whereas for Network 2 it is the same location as for the one single-phase BESS. Highest ranked location for configuration 2 is marked ' $\mathrm{B}$ ' on figures $1 \mathrm{a}$ and $1 \mathrm{~b}$ for Network 1 and 2 respectively.

Phase-balancing and phase-balancing with storage configurations provide overall improvement on all phases and reduction of network losses. The greater effect from these configurations can be achieved by placing BESS higher on the feeder, closer to substation, to supply greater number of loads with balanced voltages, yet close enough to weakest node to provide the necessary support. Intuitively, best location for BESS configuration 3 and 4 would be at or before feeder branching. Highest ranking locations for phase-balancing and phase-balancing with storage for both networks are marked with 'C' on figures $1 \mathrm{a}$ and $1 \mathrm{~b}$, for Network 1 and 2 respectively. In both cases, the locations are at the top of two branches, allowing BESS to improve the lowest voltage nodes until within the statutory limits (see table 11).

\subsection{Impact of BESS at the highest ranked Location}

For each of the network case studies, the worst case winter week scenario has been simulated with each BESS configuration located at the best location identified in Table 2. The resulting 'best possible' impacts for each BESS are described in the following sections.

\subsubsection{Network 1}

The impact of each BESS configuration network operation on day 1 at the half-hourly basis is shown on figure 4 .

The impact of phase-balancing function compared to single-phase BESS is immediately visible: power flow and line utilisation are in close proximity to each other an all phases throughout most of the day. The only significant deviation in power flow and line rating occurs around $6 \mathrm{pm}$ where a peak consumption occurs on all three phases, with Phase 1 having significantly higher peak. At this point BESS configurations 3 and 4 reach maximum power output on Phase 1 and cannot inject more power on Phase 1 . The difference between configuration 3 and 4, is that for phase balancing during peak reduction, power is transferred from other phases at the same time as the peak as opposed to absorbed from other phases by storage before the peak. For singlephase BESS, the improvement is only achieved on the phase the BESS is connected to with insignificant impact on other phases.

The results showing impact of each BESS configuration at their optimum locations are summarised in Figure 6a. For this network, the best results for all network parameters are obtained from the phase-balancing approach.

The summary of impact of each BESS configuration against baseline on Network 1 is given in figure 6a. Overall, each BESS configuration improves the network operation by increasing minimum voltage, reduction of line utilisation and losses. However, configuration 3 and 4 increase minimum voltage above the statutory constraint, reduce maximum line utilisation below recommended maximum and significantly reduces network losses. 


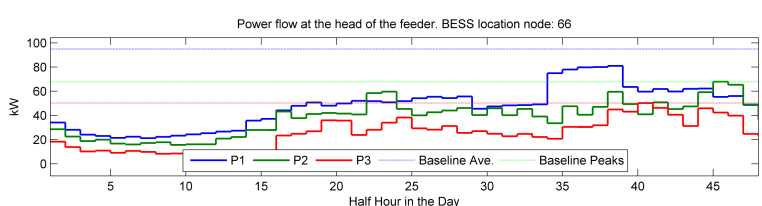

Half Hour in the Day
Minimum Ph-to-N voltage accross the day

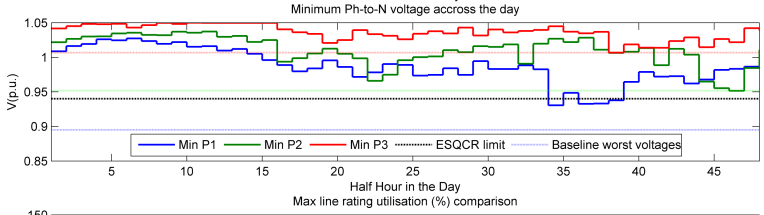

Max line rating utilisation (\%) comparison

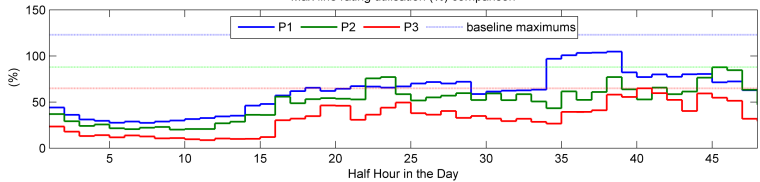

(a) Single-Phase Storage

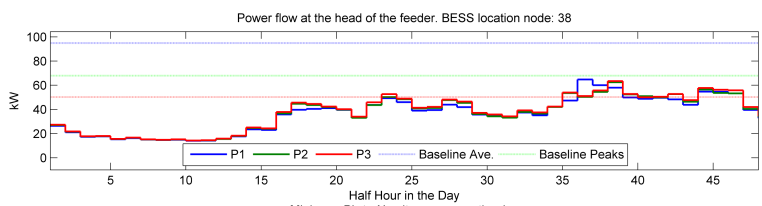
Minimum Ph-to-N voltage accross the day
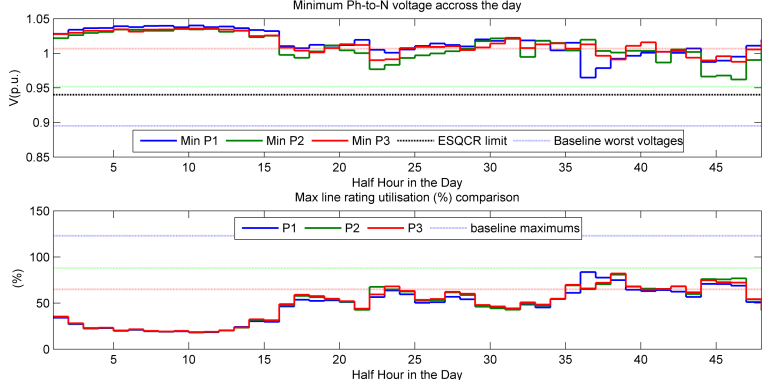

(c) Phase-Balancing Only

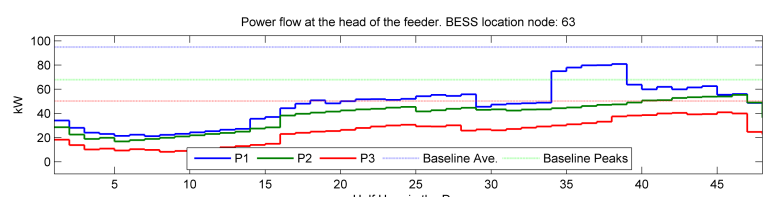

Minimum Ph-to-N voltage accross the day

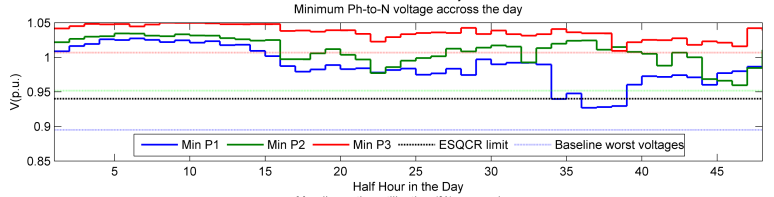
Max line rataing utilisation (\%) comparison

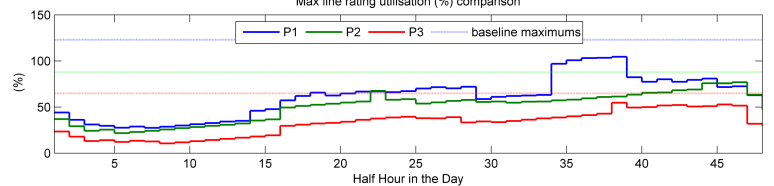

(b) Three single-Phase Storage
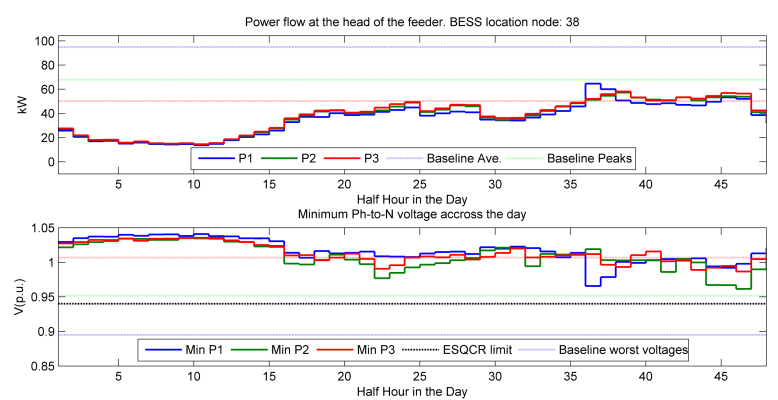
Half Hour in the Day
Max line rating utilisation (\%) comparison

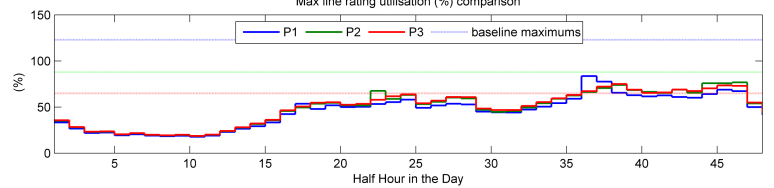

(d) Phase-Balancing and Storage

Figure 4: Comparison of losses, minimum voltage and line utilisation for Network 1

\subsubsection{Network 2}

With reference to Figure 6a, since Network 2 is more balanced compared to Network 1, pure phasebalancing configuration does not perform as well as phase-balancing with storage. At the time of highest demand, around $27^{\text {th }}$ half hour of the day (see figure $5 \mathrm{a}$ and $5 d$, the loading on three phases in more or less equal. This balanced condition does not provide any margin for configuration 3 to provide peak reduction. The addition of storage capacity to phase-balancing allows further reduce peak power demand on all three phases, hence further improving minimum voltage and losses.

\section{Discussion}

Previous sections covered the impact of each BESS configuration and its location on the network perfor- mance. The metrics for evaluating the performance are based on voltage constraints, maximum line utilisation rating and total daily losses. Figure 6 summarises the impact of each BESS configuration on the networks if BESS is installed at the recommended locations given in table 2

BESS Configuration 1, single-phase storage rated to deal with $30 \%$ of the peak and located on the most loaded phase, have improved the network operation for both networks. However, the improvement is only evident on the phase the BESS is connected to and the constraints are not resolved: Phase 1 voltage on Network 1 , Phase 2 voltage on Network 2, line utilisation on Phase 1 Network 1, and Phase 2 on Network 2.

BESS Configuration 2, co-located three single-phase storage each rated to deal with $30 \%$ of the peak, also 

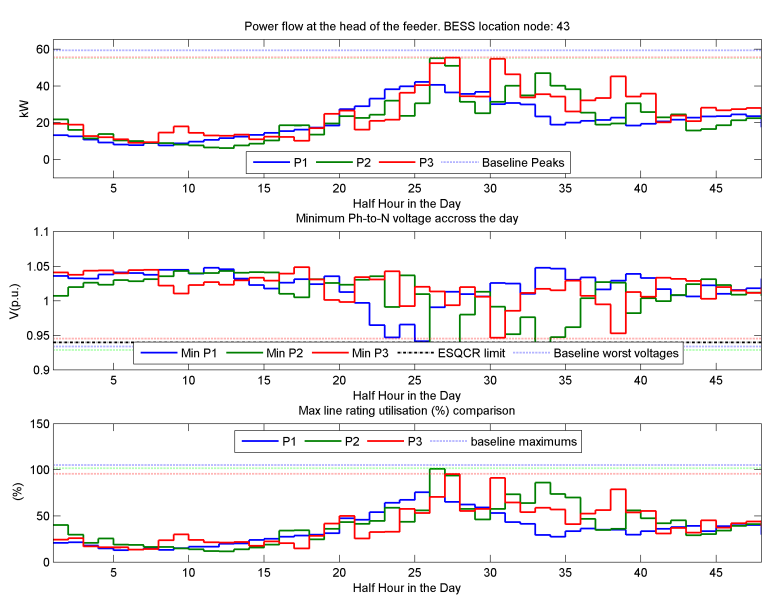

(a) Single-phase storage
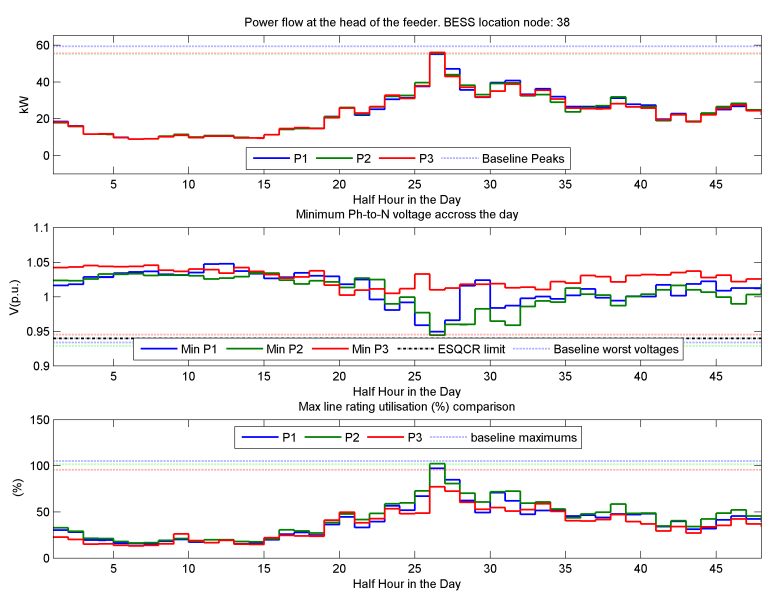

(c) Phase-balancing only
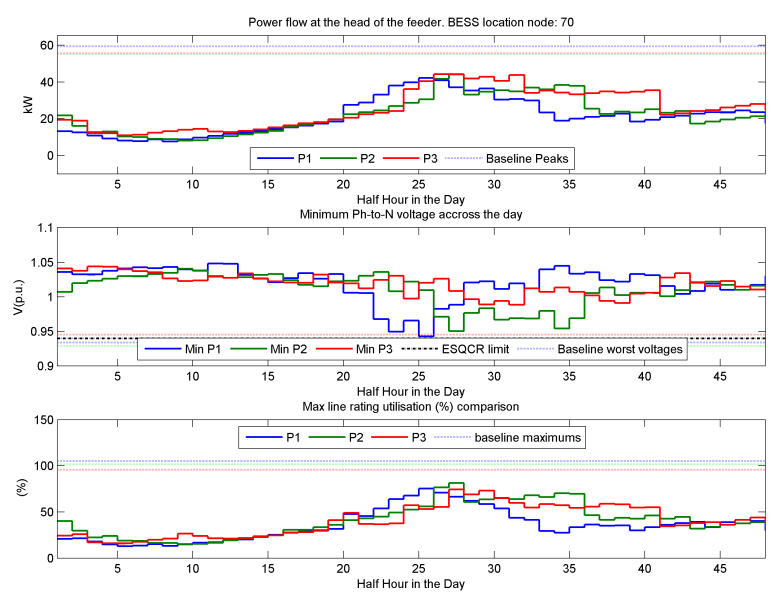

(b) Three-phase storage
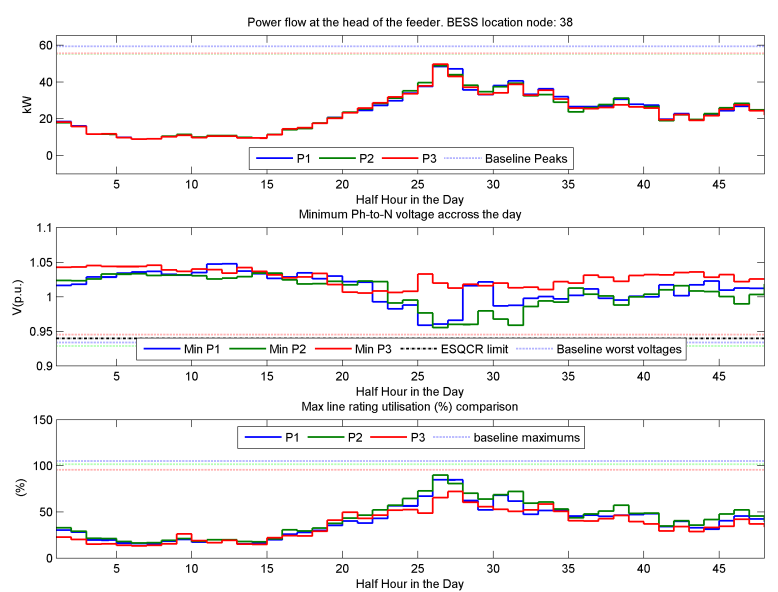

(d) Phase-balancing and storage

Figure 5: Comparison of losses, minimum voltage and line utilisation for Network 2

improved the network operation for both networks, but for Network 1 not all constraints are resolved for Phase 1. Network 2, on the other hand, all constraints are resolved and BESS configuration 2 achieved lowest daily losses.

Due to the unbalanced nature of Network 1, phasebalancing configurations of BESS have sufficiently improved network operation to alleviate voltage and thermal constraints as well as achieve significantly lower losses. The addition of storage to the phase-balancing power electronics provides greater reduction in thermal constraints and losses.

Network 2, however, is more balanced and threephase BESS configurations do not have the same effect as on Network 1. A purely phase balancing solution does not resolve thermal constraints on Phases 1 and 2 .
However, the addition of storage sized to deal with $30 \%$ of a peak on the heaviest phase achieves similar performance in thermal constraint management as the three single-phase BESS Configuration, with three times as much of storage capacity and hence cost.

The best location of the BESS is governed by the BESS configuration aligned with the structure of the network and customer behaviour. Intuitively, the greatest impact on voltages occurs when the storage is located nearest to the nodes with worst voltage drop, which is true for single-phase storage (see Figure 1a and 1b. location A. By incorporating phase-balancing, the best location for a BESS moves towards the top of the branch due to the influence of lower losses caused by supplying more balanced voltages to a greater number of customers. 

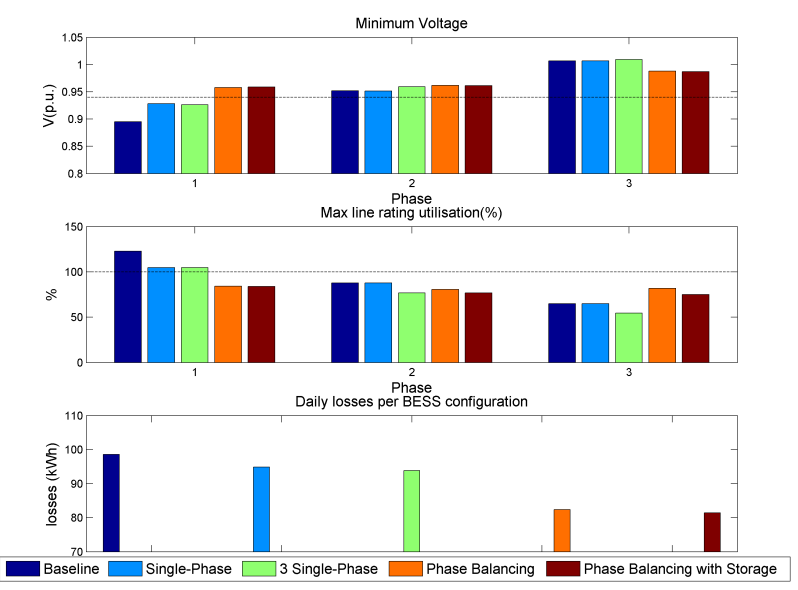

(a) Comparison of minimum voltage, maximum cable loading and losses per BESS configuration for Network 1
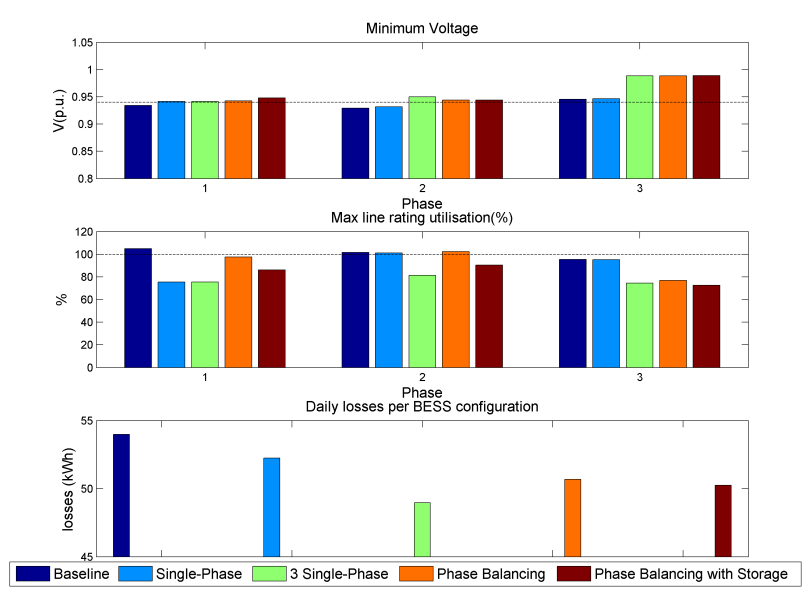

(b) Comparison of minimum voltage, maximum cable loading and losses per BESS configuration for Network 2

Figure 6: Summary of the impact of BESS locations.

Clearly the extent of the network unbalance influences the requirements on the BESS and in cases such as described above, phase-balancing operation appears to have most value. However, the fact that phase-balancing increases load on weaker phases introduces the potential for additional problems to be introduced. Yet, additional load on the weaker phases can be mitigated by including an energy storage device in combination with phase-balancing. Comparison of the configurations above shows that for the given networks, similar performance can be achieved with a third of a storage capacity compared to three single-phase BESS configuration.

\section{Conclusions}

This paper has presented an impact assessment of Battery Energy Storage Systems (BESS) configuration and location on the Operation of LV feeders. Two real UK urban networks LV feeders, with unbalanced and balanced customer connection, were analysed under worst case winter demand from real domestic profiles. The main goal of the BESS that was trialled in to the two networks was to reduce peak-demand, although performance was assessed in terms of losses, voltage and line utilisation. Four BESS configurations, with associated control algorithms, were considered: a singlephase BESS unit, three single-phase co-located storage units, three-phase power electronics unit without storage, and a three-phase BESS unit with storage.

These BESS configurations were trialled at each node in the two networks in order to determine the impact of the location and configuration of the BESS on peak reduction, voltage, losses and line utilisation. For both networks, the best locations for each BESS configuration followed a similar pattern: single phase solutions were most beneficial if placed on the branch with lowest phase voltage, and for phase-balancing configurations, the best location tended to the top of branches.

Even at the best location, single-phase configurations rated at $30 \%$ of the peak half-hourly demand did not resolve voltage and thermal constraints for the unbalanced network 1 . In contrast, phase-balancing solutions, placed at a top of two branches within this unbalanced network were shown to balance the power flow across phases and significantly improved network operation, resolving all voltage and thermal issues.

For Network 2, being more balanced, the pure phasebalancing configuration did not provide the required improvement. Voltage and thermal issues were only resolved by placing three single-phase BESS or phasebalancing with storage; the storage was essential to mitigating peak demand that was synchronised across all phases. However, the required energy storage capacity of the phase-balancing and storage configuration was shown to be only a third of the three single-phase storage units.

Fundamentally, this work and results presented in this paper has demonstrated that the location and configuration of a BESS has a significant impact on the resulting impact the BESS has on the local network. Key observations are that for an unbalanced network, the most cost effective solution may be to deploy either a singlephase BESS or a power-electronic system without stor- 
age. On balanced networks, a three-phase BESS can be configured with less storage capacity than single-phase BESS and achieve the same or better performance.

\section{Acknowledgements}

The work has been carried out with Scottish and Southern Energy Power Distribution via the New Thames Valley Vision Project (SSET203 New Thames Valley Vision), funded by the Low Carbon Network Fund established by Ofgem.

\section{References}

[1] DECC, The UK Low Carbon Transition Plan: National strategy for climate and energy, Tech. rep. (2009).

[2] Royal Academy of Engineering, Generating the Future: UK Energy Systems Fit for 2050, Tech. rep. (2010)

[3] National Grid, UK Future Energy Scenarios, Tech. Rep. July (2013).

[4] DECC, 2050 Pathways Analysis, Tech. Rep. July (2010). arXiv: 764 doi:Ref : 10D/764

[5] A. Poghosyan, D. V. Greetham, S. Haben, T. Lee, Long term individual load forecast under different electrical vehicles uptake scenarios, Applied Energydoi:10.1016/j . apenergy . 2015. 02.069

[6] G. Ault, D. Frame, N. Hughes, N. Strachan, Electricity Network Scenarios for Great Britain in 2050 (2008).

[7] ENSG, A Smart Grid Vision, Tech. Rep. November (2009).

[8] ENSG, A Smart Grid Routemap, Tech. rep. (2010).

[9] EU, EU Commission Task Force for Smart Grids Expert Group1 Final Deliverable: Functionalities of smart grids and smart meters (2010).

[10] A. Urquhart, D. MacLeman, Lenf tier 1 close-down report orkney energy storage park (sset1007), Tech. rep., SSEPD (2013).

[11] UK Power Networks, Design and Planning considerations for large-scale distribution-connected energy storage (SNS1.2), Tech. rep., UK Power Networks (2013).

[12] N. Coote, LCNF Tier 1 Close-Down Report 1MW Battery, Shetland (SSET1001), Tech. rep., SSEPD (2014).

[13] S. Kaushik, SoLa Bristol: Early learning report, Tech. rep., University of Bath (2014).

[14] A. Steele, LCNF Tier 1 Closedown Report Low Voltage Connected Energy Storage (SSET1008), Tech. rep., SSEPD (2014).

[15] M. Coulthard, G. Hewitt, LCNF Tier 2 SDRC 9.4 ( c ) Evidence Report Install 25 LV Connected Batteries (SSET203 NTVV), Tech. rep. (2015).

[16] M. Rowe, T. Yunusov, S. Haben, C. Singleton, W. Holderbaum, B. Potter, A peak reduction scheduling algorithm for storage devices on the low voltage network, IEEE Transactions on Smart Grid 5 (4) (2014) 2115-2124. doi:10.1109/TSG. 2014 . 2323115

[17] M. Rowe, T. Yunusov, S. Haben, W. Holderbaum, B. Potter, The real-time optimisation of DNO owned storage devices on the LV network for peak reduction, Energies 7 (6) (2014) 3537-3560. doi:10.3390/en7063537

[18] N. S. Wade, P. C. Taylor, P. D. Lang, P. R. Jones, Evaluating the benefits of an electrical energy storage system in a future smart grid, Energy policy 38 (11) (2010) 7180-7188.
[19] Scottish and Southern Energy Power Distribution, New Thames Valley Vision

URL http://www.thamesvalleyvision.co.uk/

[20] Irish Social Science Data Archive, CER Smart Metering Project (2012).

[21] Department of Trade and Industry, Guidance on The Electricity Safety, Quality and Continuity Regulations 2002, Report Number: URN 02/1544 (October) (2002) 1-47.

[22] C. J. Bennett, R. a. Stewart, J. W. Lu, Development of a threephase battery energy storage scheduling and operation system for low voltage distribution networks, Applied Energy 146 (2015) 122-134. doi:10.1016/j.apenergy.2015.02.012

[23] R. Arghandeh, J. Woyak, A. Onen, J. Jung, R. P. Broadwater, Economic Optimal Operation of Community Energy Storage Systems in Competitive Energy Markets, Applied Energy 135 (2014) 1-17. doi:10.1016/j.apenergy.2014.08.066

[24] N. Wade, P. Taylor, P. Lang, P. Jones, Evaluating the benefits of an electrical energy storage system in a future smart grid, Energy Policy 38 (11) (2010) 7180-7188. doi:10.1016/j . enpol.2010.07.045

[25] O. Anuta, A. Crossland, D. Jones, E. Uk, N. Wade, Regulatory and financial hurdles for the installation of energy DNO financial / regulatory issues, in: CIRED Workshop, no. May, 2012.

[26] F. Shahnia, P. J. Wolfs, A. Ghosh, Voltage unbalance reduction in low voltage feeders by dynamic switching of residential customers among three phases, IEEE Transactions on Smart Grid 5 (3) (2014) 1318-1327. doi:10.1109/TSG . 2014. 2305752

[27] Y. Yang, H. Li, A. Aichhorn, J. Zheng, M. Greenleaf, Sizing Strategy of Distributed Battery Storage System With High Penetration of Photovoltaic for Voltage Regulation and Peak Load Shaving, ieeexplore.ieee.org (2013) 1-10 